\title{
The Hermeneutics of Participation of Transgender Athletes in Sports - Intensifying Third Force
}

\author{
Baljinder Singh, Kanwaljeet Singh
}

Guru Nanak Dev University, Amritsar, Punjab, India

ABSTRACT

The present paper is an attempt to move structurally towards the understanding of the basic constitution of the core concept of this paper. It's basically looking at the empirical and inner ideological conception of issue of participation of transgender athletes in sports. The creed of the Olympics states: "The important thing in the game is not winning but taking part. The essential this is not conquering, but fighting well". As noble a goal as this is, it has little to do with the reality of the modern sports world. Athletes are rewarded for winning at virtually every level of competition. Second place is viewed as the "first loser". Modern sports' and the media's misplaced fixation on fame, fortune and winning at all costs have unintentionally created a growing market for unhealthy practices. This review manifests an attempt towards the conceptual study of the participation of transgender athletes in competitive sports, which is one of the latest equality challenges for sportgoverning organizations worldwide. The paper investigates the motif of interrelated dynamics between gender terminology and legal and medical issues related to transgender athlete participation in sport. On 28 October 2003, an ad-hoc committee convened by the International Olympic Committee (IOC) Medical Commission met in Stockholm to discuss, then issue recommendations on, the topic of the participation of individuals who have undergone sex reassignment (male to female and vice versa) in sport. This has resulted in a heated debate that there is a competitive advantage for a male who has undergone sex reassignment surgery because of his physical training and development. Men have significantly higher levels of testo-sterone, a greater muscle-to-fat ratio, and greater heart and lung capacity than women. The other side of the debate argues that a physiological advantage does not necessarily exist. Transgenders must continually take massive doses of oestrogen, which decreases their strength, and their bodies no longer produce testosterone. The issue under consideration has multi-faceted dimensions of interpretations that center on a desire to 'deconstruct' the present structuration of acceptance of sex and gender terminology. The resultant aim is to create a worldview of equality, respect for the 'other', and competitive fairness. The latent attempt of the paper is to deconstruct the binary of inequality in the field of sports with a view to give vibrational impetus for attaining the ideals of equality in sports.

KEYWORDS

transgender athletes, International Olympic Committee (IOC), cultural constructs of society 


\section{Introduction}

Sport performance has taken a great leap forward in the last 20 years. Technology has greatly enhanced our level of performance through improved equipment and improved nutritional products. Back in the 1980's it was good enough to be fitter than your opponent, thus securing a win; it was good enough to have more technical skills, thus ensuring the upper hand; even having tactical skills would allow for an advantage. Today however, everybody is as fit, as technically and as tactically advanced as his or her opponent. The playing field has been leveled once again. What could possibly give us the edge that we are desperately looking for to give us the one up on our opponents? This has manifested itself in the development of changing social views and laws affecting sexuality, and may give rise to number of cases of transgender athletes in sports. The inclusion of transgender athletes is one of the latest equality challenges for sport governing organizations worldwide. No sport organization prior to 2003 had any policy at all governing the participation of transgender athletes. Significant technological advancements in the domain of genetics have revamped the postmodern concept of sport.

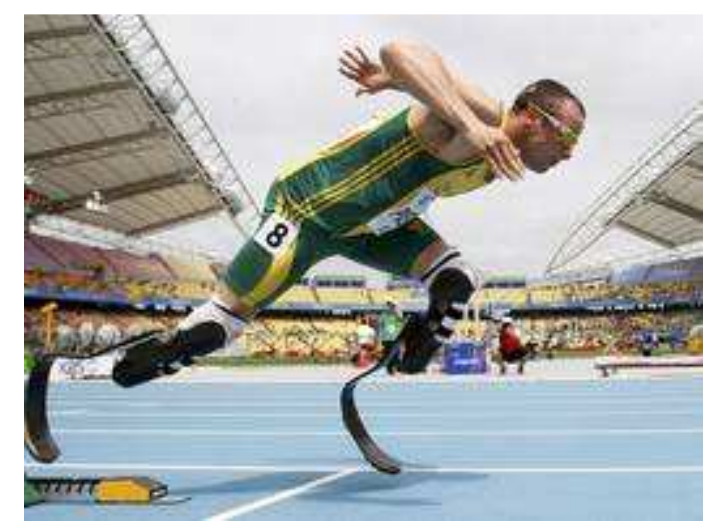

Figure 1. Oscar Leonard Carl Pistorius

Source: http://en.wikipedia.org/wiki/Oscar_Pistorius

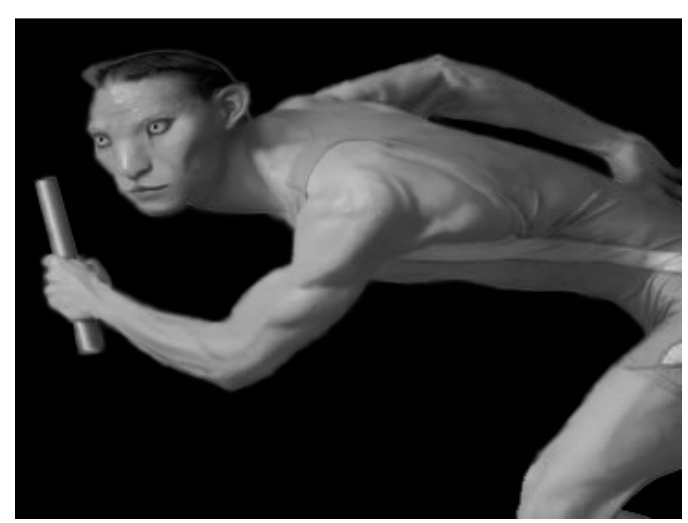

Figure 2. Genetically modified athlete Source: http://ebooks.ebookmall.com/ebook/272438 -ebook.htm

\section{Discussion and analysis}

Gender has for many years been an issue that surfaces from time to time in women's events at athletic meets. Women's participation in sport has a long history. It is a history marked by division and discrimination. The positive outcomes of sport for gender equality and women's empowerment are constrained by gender-based discrimination in all areas and at all levels of sport and physical activity, fuelled by the continuing stereotypes of women's physical abilities and social roles. For women, participation in sport is often discouraged because it is still seen as contrary to societal norms for being feminine or womanly. Beginning in the mid-1960s, female athletes competing at the international level were required to undergo gender verification tests to make sure that they were not actually men posing as women. Gender verification for the purpose of competition has undergone significant evolution since attempts were made to introduce measures aimed at ensuring fair competition amongst female athletes. The first mechanism (introduced for international competition in the mid-sixties) involved rather crude and perhaps humiliating physical examinations. This very quickly gave way to the method of determining 'sex' chromatin through buccal smear examination. However, as there were too many uncertainties associated with this method, many experts in the field clamored for its termination, resulting in it being abandoned first by the IAAF in 1991, and then the IOC since Sydney 2000. Women's participation in sports has a long history, although certain traces of discrimination can also be found in a logocentric conception of the world. The wave of fairness includes a transparent testing protocol. 


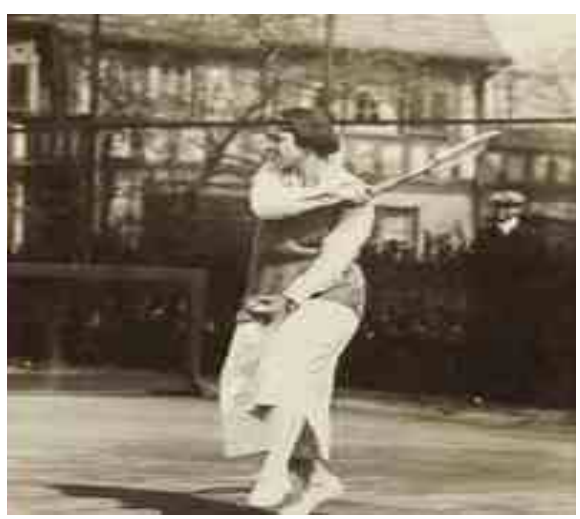

Figure 3. Molla Mallory: Mould Breaker and Mould Maker of Women's Tennis

Source: http://bleacherreport.com/articles/267135

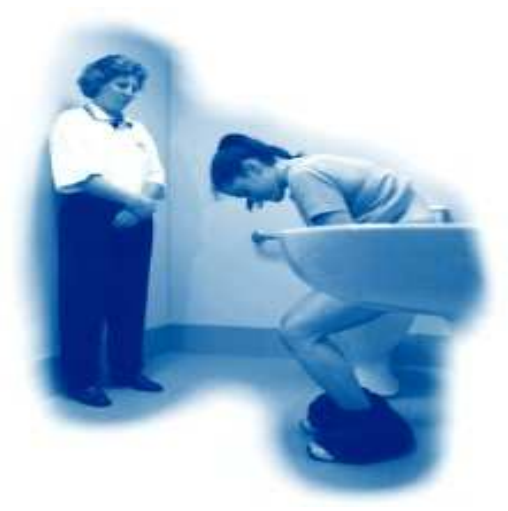

Figure 4. A chaperone of the same sex as the athlete will oversee the passing of the sample

Source: http://bleacherreport.com/articles/267135

Sport has been considered a space in which traditional gender norms are reinforced. In the last 45 years, 'gender' has been understood as different from 'sex' by reference to a difference between the body, biology, and being male or female ('sex'), as well as the social and cultural roles inscribed on bodies; masculinity and femininity ('gender'). But originally, the categories 'male' and 'female' were understood as residing in one body, and sex was a sociological category rather than a biological one (Laquer 1990). The idea that there was a male and female 'sex' in one body was superseded by the concept of two 'sexes' based on bodily differences between the reproductive organs, which became the foundation of sex difference in the eighteenth century (Stoller 1968). The sex/gender distinction was developed in research on intersex people in the 1950s, which later gave rise to transsexual identities in the 1960s (Prosser 1998).

\section{Testing the gender boundaries}

Gender-verification tests at international competitions were instituted as a result of a heightened awareness that athletes were taking performance-enhancing drugs that gave them a "male advantage". Suspicion that a number of Soviet and East German female athletes were not really women added to the climate of distrust. These concerns took on special importance during the cold war, when mistrust between nations of the West and those of the Soviet Union and East Block dominated the international arena. Sex-reassignment surgeries of some former Olympic athletes intensified the controversy, as did the highly publicized revelation that a German athlete who had set a world record in the women's high jump in 1938 was male. The International Olympic Committee (IOC) and the International Amateur Athletics Federation (IAAF) decided to require that all female athletes be tested to ensure their "femininity" and to disqualify those with a presumed unfair "male advantage". The first tests were "naked parades", where women were required to walk nude before a panel of judges and to undergo gynecological examinations. The physical exams were soon augmented by sex chromatin testing, a short-lived test that looked for a Barr body, the inactivated second X chromosome found in female cells. The Barr body test was replaced by karyotyping, which in turn was succeeded by SRY analysis, a direct test for the presence of the single-most important gene in male development. Unfortunately, IOC officials did not appreciate the complexity of human sex determination. After three decades of intense debate between scientist and physicians, and just before the 2000 Olympics in Sydney, the IOC abolished routine gender testing.

\section{Transgendered athletes creating a passive space in sport}

The most recent and controversial decision on gender by the IOC came on May 27, 2004, when the IOC Executive Committee decided to allow transsexuals to compete in the Olympics and opened the way for transsexual athletes to compete in the 2008 Beijing Olympics. Transsexuals, male-to 
female or female-to-male, must meet three requirements to compete: "Completion of surgical anatomical changes, including external genitalia changes and gonadectomy; legal recognition of assigned sex by the appropriate official authorities; and sufficiently long and verifiable administration of hormonal therapy appropriate for the assigned sex to minimize gender-related advantages in sport competitions. Eligibility should begin no sooner than two years after gonadectomy." The quoted guidelines have brought a revolutionary change with respect to perceiving the issue that carries almost opposite significance per the 'way of the world'. However, it has opened up new frontiers of deliberation to bring about empirical and qualitative understanding pertaining to the issue under consideration. The maddening race for success has changed the ethics of sports and new variation/deviation have come in the forefront in recent times.

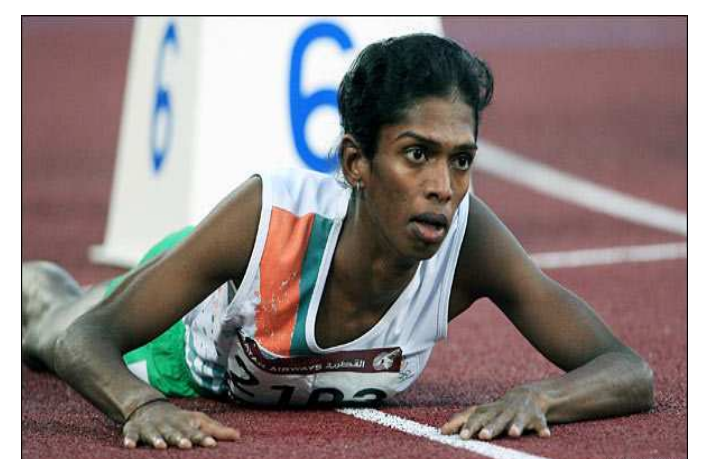

Figure 5. Indian runner Santhi Soundarajan Source:http://www.bbc.co.uk/blogs/gordonfarquhar /2009/08/this_must_be_an_awful.html

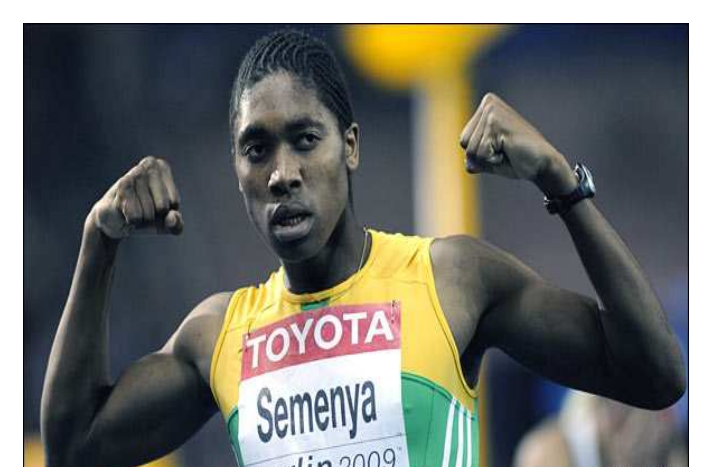

Figure 6. South African runner Caster Semenya Source:http://www.bbc.co.uk/blogs/gordonfarquhar /2009/08/this_must_be_an_awful.html

\section{Sport in the 21 st century constructs inimitable challenges for trans-athletes}

A broad spectrum of identities is included under the umbrella of transgender identity. Transsexual or transitioned athletes may pose the greatest challenge to equity in sex-segregated sport competition. Athletes who have completed the transition from male to female are most likely to be seen as having an unfair competitive advantage in contests against women who are female at birth. Athletes who have completed a transition from female to male also pose challenges if they are taking testosterone as part of their hormone therapy due to concerns about athletes' use of performance enhancing drugs. Other transgender athletes - whose gender identity does not match their birth sex, but do not undergo surgery or take hormones - pose less of a competitive equity challenge. Instead, they present a challenge to traditional gender expectations and might be subjected to discrimination or harassment because of stereotypes or prejudice. Athletes whose gender expression is non-conforming, but whose birth sex and gender identity match (i.e. masculine women or feminine men) pose the least challenge to competitive equity. However, these athletes might be subjected to discrimination or harassment based on their gender expression. The tides of changes have engulfed the social phenomenon with special references to hermeneutics to genders.

\section{Conclusion and practical implications}

The focus of the current paper is to decipher the motif of dismantling the existing structure of belief-system pertaining to the issue under consideration. The inner constitution offers certain novel meta-structures to understand the reality in this context. The IOC has made an inevitably arbitrary decision regarding the participation of sex-reassigned transsexuals in elite sports (Gooren, 2008). The IOC's transsexual policy as currently stated is deficient. More specifically, the IOC has not sufficiently demonstrated that transsexual athletes do not have competitive advantages over typically gendered athletes. It is the responsibility of the IOC to reduce the various doubts about transsexual athletics. It is clear that, from the scientific, socio-cultural and ethical criticisms outlined in this paper, sex-testing (gender verification) was/is inappropriate. When it comes to gender testing, the policy of the IOC had to be rethought: the policy was criticized because it involved only testing women to ascertain their 


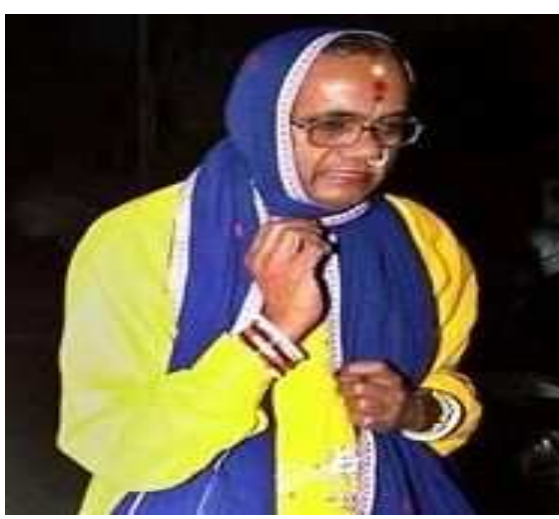

Figure 7. Uttar Pradesh Inspector General of Police D K Panda declaring himself as Radha

Source: $\quad$ http://news.bbc.co.uk/2/hi/south_asia/4440 504.stm

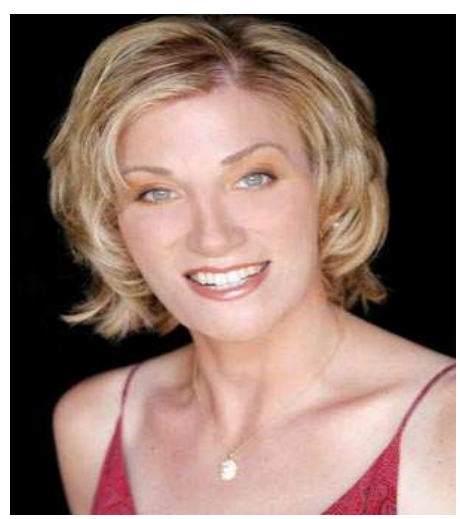

Figure 8. First male-to-female golfer: Mianne Bagger

Source:http://www.theage.com.au/articles/ 2004/11/04/1099547318148.html?from=storylhs

gender. With a view to evolve the holistic understanding of the issue in question, an international debate of intellectuals belonging to various knowledge disciplines should be initiated. It seems that the biggest obstacle facing trans-athletes is a serious lack of understanding and compassion from teammates, coaches and fans. Unfortunately, many coaches, parents, sports psychologists and administrators are ill equipped to create welcome space for trans-athletes; instead, such people simply reinforce old stereotypes. Only medical and physiological research was consulted to develop the Stockholm consensus, leading to a policy that does not fully consider its effects on all trans-athletes.

\section{REFERENCES}

Gooren, J.G. \& Bunck, C.M. (2004). Transsexuals and Competitive Sports. The Netherlands. European Journal of Endocrinology, 151, 425-429.

Louis, J.G. (2008). Hormone Doping: Detection and Deterrence Olympic Sports and Transsexuals. Asian Journal of Andrology, 10, 427-432.

Laqueur, T. (1990). Making Sex: Body and Gender from the Greeks to Freud. Cambridge, MA: Harvard University Press.

Lyotard, J.F. (1989). The Postmodern Condition: A Report on Knowledge (pp. 178-179). Minneapolis: University of Minnesota Press.

Louis, J.G. (2008). Hormone Doping: Detection and Deterrence Olympic Sports and Transsexuals. Asian Journal of Andrology, 10, 427-432.

Prosser, J. (1998). Second Skins: The Bodily Narratives of Transsexuality. New York: Columbia University Press.

Stoller, R.J. (1968). Sex and Gender: On the Development of Masculinity and Femininity. New York: Science House.

\section{AUTHOR'S ADDRESS: $\quad$ Baljinder Singh al}

Department of Physical Education (T)

Guru Nanak Dev University,

Amritsar, Punjab, India

Email: bal_baljindersingh@yahoo.co.in 